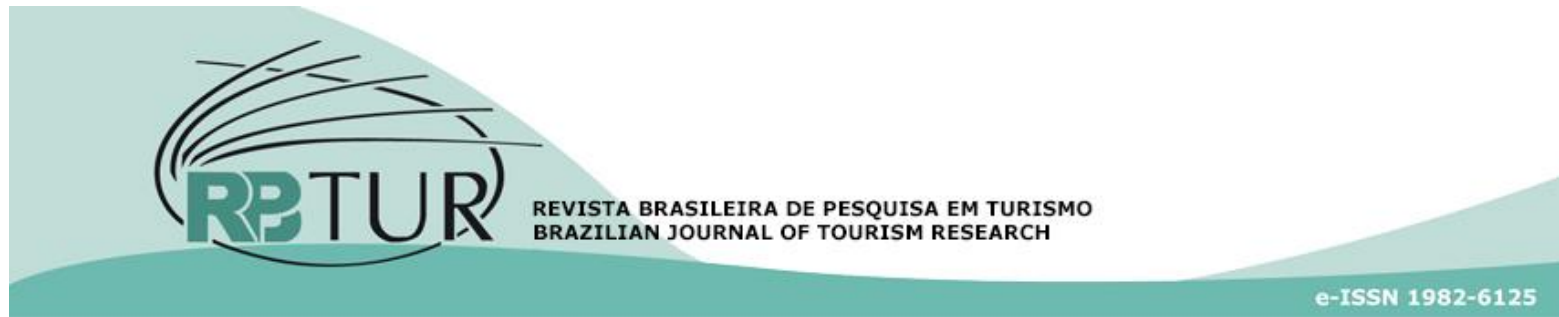

\title{
Artigos
}

\section{Turismo Gastronômico como objeto de pesquisa: análise das publicações em periódicos brasileiros (2005-2017)}

\author{
Food Tourism as research object: analysis of the publications in Brazilian \\ periodicals (2005-2017)
}

\section{Turismo Gastronómico como objeto de investigación: análisis de las publicaciones en periódicos brasileños (2005-2017)}

\author{
Maria Henriqueta Sperandio Garcia Gimenes Minasse ${ }^{1}$ \\ 1Universidade Anhembi Morumbi (UAM), São Paulo, Brasil.
}

Palavras-chave:

Turismo gastronômico Pesquisa científica; Artigos em periódicos; Brasil.

Keywords:

Food tourism; Scientific research; Journal articles; Brazil.
Resumo

Este artigo busca compreender como a pesquisa sobre o Turismo Gastronômico vem se desenvolvendo, a partir da análise da produção científica publicada em periódicos brasileiros dedicados ao turismo e à hospitalidade com avaliação Qualis CAPES igual ou superior à B5; identifica os periódicos que publicaram estudos sobre o tema; verifica a distribuição dos artigos por estrato Qualis, por periódico, por ano e por temáticas/subtemáticas; identifica os procedimentos metodológicos; caracteriza o perfil dos autores que se dedicam ao tema com assiduidade. É uma pesquisa qualitativa, baseada em princípios da análise de conteúdo (Bardin 2011), com corpus analítico de 89 artigos publicados entre 2005 e 2017. Principais resultados: as Revistas Rosa dos Ventos e Turismo em Análise publicaram o maio número de artigos; $24,71 \%$ dos artigos pertencem ao estrato B1/Qualis; o ápice de publicações foi 2017 (16,85\%). Foram identificadas 8 temáticas e 11 subtemáticas, destacandose Gastronomia como Atrativo Turístico e Turismo de Bebidas. Turismo de Bebidas/enoturismo foi a temática mais desenvolvida (28,09\%). Os descritivos metodológicos são, de maneira geral, superficiais, com prevalência de pesquisas qualitativas (92,14\%). Pesquisa bibliográfica e entrevistas são as estratégias de coleta de dados mais utilizadas. Poucos pesquisadores $(13,20 \%)$ publicaram dois ou mais artigos sobre o tema.

Abstract

This article aims to understand the development of Food Tourism research by analyzing articles published in Brazilian tourism and hospitality journals listed in B5 or higher strata of Qualis CAPES evaluation; it identifies journals that have published articles on the subject; examines the distribution of articles per Qualis stratum, per journal, per year, and per topic/subtopic; identifies the methods used; characterizes the profiles of authors publishing frequently on Food Tourism topics. This is a qualitative study, based on content analysis (Bardin, 2011), with a corpus of 89 articles published between 2005 and 2017. Main results: Rosa dos Ventos and Turismo em Análise journals published the largest number of articles; $24.71 \%$ of the articles are in B1/Qualis stratum journals; 2017 was the year with 
Palavras clave:

Turismo gastronómico; Investigación científica; Artículos en periódicos; Brasil.

Revisado por pares. Recebido em: 14/03/2019. Aprovado em: 29/04/2019.

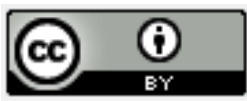

the most publications (16.85\%). Eight topics and 11 subtopics were identified, with emphasis on Gastronomy as Tourist Attraction and Beverage Tourism. Beverage Tourism/wine tourism was the most developed topic (28.09\%). The method description is, in general, superficial, with predominance of qualitative research (92.14\%). Bibliographical research and interviews are the most commonly used data collection strategies. Few researchers $(13.20 \%)$ have published two or more articles on the subject.

Resumen

Este artículo busca comprender cómo la investigación acerca del Turismo Gastronómico se viene desarrollando, a partir del análisis de la producción científica publicada en periódicos brasileños dedicados al turismo y la hospitalidad con evaluación Qualis CAPES igual o superior a la B5; identifica los periódicos que publicaron estudios sobre el tema; se comprueba la distribución de los artículos por estrato Qualis, por periódico, por año y por temáticas/subtemáticas; identifica los procedimientos metodológicos; y caracteriza el perfil de los autores que se dedican al tema con asiduidad. Es una investigación cualitativa, basada en principios del análisis de contenido (Bardin 2011), con corpus analítico de 89 artículos publicados entre 2005 y 2017 . Principales resultados: las Revistas Rosa de los Vientos y Turismo en Análisis publicaron el mayor número de artículos; $24,71 \%$ de los artículos pertenecen al estrato B1/Qualis; el ápice de publicaciones fue 2017 (16,85\%). Se identificaron 8 temáticas y 11 subtemáticas, destacándose Gastronomía como Atractivo Turístico y Turismo de Bebidas. Turismo de Bebidas/enoturismo fue la temática más desarrollada (28,09\%). Los descriptivos metodológicos son, de manera general, superficiales, con prevalencia de investigaciones cualitativas (92,14\%). La investigación bibliográfica y las entrevistas son las estrategias de recolección de datos más utilizadas. Pocos investigadores (13,20\%) publicaron dos o más artículos sobre el tema.

Como citar: Minasse, M. H. S. G. G. (2020). Turismo Gastronômico como objeto de pesquisa: análise das publicações em periódicos brasileiros (2005-2017). Revista Brasileira de Pesquisa em Turismo, São Paulo, 14 (1), p. 92-111, jan./abr. http://dx.doi.org/10.7784/rbtur.v14i1.1669

\section{INTRODUÇÃO}

O cenário gastronômico ocidental sofreu alterações significativas nas últimas décadas, compreendendo a expansão da indústria alimentar e do mercado de alimentação fora do lar, a articulação de políticas públicas para a salvaguarda do patrimônio alimentar e a multiplicação das novas formas de 'entretenimento gastronômico' (como programas de tevê). Como observa Kesimoglu (2015), o aumento do interesse pela comida em mídias, negócios e entretenimento contagiou o interesse acadêmico.

Diferentes disciplinas - a administração, a antropologia, a história, a nutrição e a sociologia - se debruçaram sobre a gastronomia com interesse renovado, movimento que também pode ser percebido no contexto acadêmico da hospitalidade e do turismo. Getz, Robinson, Anderson \& Vujicic $(2014$, p.6) defendem que "Food Tourism has attracted significant scholarly attention over the past decade, and given that the proclivity of travelers for food experiences is projected to increase, this trend is likely to continue".

No que tange à realidade brasileira, embora existam iniciativas como as de Barbosa e Collaço (2018) e de Ribeiro-Martins e Silveira-Martins (2018), não há uma análise das características do corpus geral da produção científica dedicada à temática do turismo gastronômico. São desconhecidos o volume e as características das publicações em periódicos nacionais. Considerando o interesse que o tema vem recebendo e os desafios inerentes ao desenvolvimento de pesquisas na área, acredita-se que uma análise abrangente, tendo como escopo o quadro geral destas contribuições, possa assinalar tendências, lacunas e oportunidades de pesquisa.

Este artigo objetiva analisar a produção científica dedicada ao Turismo Gastronômico veiculada em periódicos brasileiros em operação da área de turismo e hospitalidade, com conceito igual ou superior a B5 obtido na avaliação Qualis CAPES ${ }^{1}$ do período de 2005 a 2017 (área Administração Pública e de Empresas, Contabilidade e Turismo). De forma específica, procura-se identificar os periódicos que publicaram estudos sobre o tema; verificar a distribuição dos artigos por estrato Qualis, por periódico, por ano de publicação e

1 Conjunto de procedimentos utilizados pela Capes para estratificar a qualidade da produção intelectual dos PPG a partir da análise da qualidade dos periódicos científicos, sendo A1 o estrato mais alto e B5 o mais baixo (CAPES, 2018). 
por temáticas e subtemáticas trabalhadas; identificar os procedimentos metodológicos utilizados; e caracterizar o perfil dos autores que se dedicaram ao Turismo Gastronômico com assiduidade. Trata-se de uma pesquisa de caráter descritivo e analítico cujos procedimentos de coleta e análise de dados serão descritos no item específico.

\section{REVISÃO DE LITERATURA}

A alimentação é uma prática cultural complexa, que extrapola o aspecto meramente fisiológico e pode apresentar múltiplos significados, incluindo ideologias, questões relacionadas à fé religiosa e à identidade cultural. Como destaca Barthes (1997), quando um indivíduo compra um alimento ou o consome, seja em práticas alimentares corriqueiras ou de caráter hedônico, ele está se comunicando com o mundo. Boutaud (2011) e Montandon (2011) defendem que compartilhar uma refeição, ato denominado comensalidade, é um elemento central da hospitalidade e da sociabilidade humana: com o alimento e a bebida acolhe-se o visitante, garante-se seu bem-estar físico e seu prazer. No contexto turístico as práticas e serviços de alimentação podem agregar valor a outros produtos e serviços turísticos, bem como serem oferecidos como atrativos turísticos propriamente ditos. Nessa condição, os atrativos podem dar origem a um segmento turístico denominado Turismo Gastronômico.

\subsection{Reflexões sobre os termos “Gastronomia" e "Turismo Gastronômico"}

O termo gastronomia foi usado pela primeira vez no século 4 a.C. na Grécia Antiga (Santich, 2004) e, desde então, tem assumido diferentes usos². Scapato $(2002$, p.3) resume a variedade de conceituações: "On one hand, gastronomy is simply related to the enjoyment of the very best in food and drink. On the other, it is a far-reaching discipline that encompasses everything into which food enters, including all things we eat and drink".

Collaço (2013) destaca dois usos contemporâneos do termo: (a) um que designa um conjunto de cozinhas presentes distintos imaginários (local, regional, nacional, popular, refinado, etc.), e (b) outro referente ao conhecimento e ao consumo de produtos diferenciados associados ao 'bom gosto' e distinção. É possível identificar dois outros usos: (c) uma área de estudo das relações entre a cultura e a alimentação, incluindo os conhecimentos das técnicas culinárias ${ }^{3}$, além dos aspectos simbólicos e subjetivos que influenciam e orientam a alimentação humana (Gimenes, 2010); e (d) uma área de atuação profissional que compreende a concepção, o planejamento, o gerenciamento e a execução de produções culinárias em diferentes fases dos serviços de alimentação, além da coordenação de empreendimentos e negócios gastronômicos (Brasil, 2016). Esta polissemia permite prever a multiplicidade de abordagens dos estudos relacionados à gastronomia.

Em publicações nacionais (mesmo as não-acadêmicas como as do Ministério do Turismo ${ }^{4}$ ) o termo Turismo Gastronômico é o utilizado, não sendo observadas variações como "Turismo Culinário" ou "Turismo Alimentar"5. Já na literatura em língua inglesa verificam-se diferentes expressões, como Culinary Tourism, Gastronomic Tourism, Gastronomy Tourism e Food Tourism, ora usadas como sinônimos, ora com sutis diferenças. Para ilustrar esse uso indistinto das várias expressões, pode-se mencionar a primeira edição do Global Report on Food Tourism (UNWTO, 2015) que, apesar de ter 'gastronomy tourism' em seu título, utiliza 'Gastronomic Tourism' e ‘Food Tourism' ao apresentar a definição do segmento:

One of the most utilized definitions of gastronomic tourism used in literature is that proposed by Hall and Sharples (2003), according to which Food Tourism is an experiential trip [...] Thus, the experience of gastronomic tourism is considered as such, provided that everything mentioned above constitutes

\footnotetext{
2 Para uma retrospectiva sintética do termo gastronomia consultar Santich (2004).

${ }^{3}$ Culinária pode designar tanto técnicas utilizadas no preparo de alimentos quanto um conjunto de pratos e bebidas associados a uma região. Neste caso, o termo "culinária baiana" tem o mesmo sentido de "gastronomia baiana" e ou "cozinha baiana".

${ }^{4}$ Em 2010, na terceira edição do Manual do Turismo Cultural, o MTUR incluiu o turismo gastronômico como um subtipo do turismo cultural.

${ }^{5}$ Costa (2012) utiliza o termo "turismo gourmand" para se referir às experiências turísticas relacionadas à alta gastronomia. Contudo, trata-se de uma ocorrência isolada.
} 
the main reason or motivation to travel for visitors to a particular destination or at least one significant reason (Herrera, Herranz \& Arilla, 2015, p. 6) [grifo nosso].

‘Gastronomic Tourism' e 'Food Tourism' são usados na publicação como sinônimos. Contudo, a segunda edição do documento, também intitulada Global Report on Gastronomy Tourism (UNWTO, 2017) adota em seu interior apenas Food Tourism, mantendo um alinhamento conceitual com a primeira edição. Este termo, inclusive, é o de maior recorrência na literatura publicada em inglês.

O conceito de Food Tourism adotado pela UNWTO $(2015,2017)$ é de Hall \& Sharples (2003) e dá ênfase às viagens experienciais para regiões gastronômicas com fins de lazer, incluindo visitas a produtores de alimentos, festivais e feiras gastronômicas, mercados de agricultores, degustações de produtos alimentícios de qualidade ou qualquer atividade de turismo relacionada à alimentação. 0 interesse por estas viagens são ligados à experimentação, ao aprendizado de diferentes culturas, à aquisição de conhecimento relacionados aos produtos turísticos e especialidades culinárias locais.

Getz et al. (2014, p.6) definem Food Tourism como “[...] travel for specific purpose of enjoying food experiences" e indicam o Turismo de Bebidas (Beverage Tourism) como uma de suas subcategorias, mencionando o enoturismo, o turismo cervejeiro, de café, de chá e de whisky como suas especializações. Destas, destaca-se o enoturismo (wine tourism), baseado na "[...] visitation to vineyards, wineries, wine festivals and wine shows for which grape wine tasting and/or experiencing the attributes of a grape wine region are the prime motivating factors for visitors and its best seen as a specific subset of the more general concept of Food Tourism" (Hall \& Sharples, 2003, p. 9-10). Herrera, Herranz \& Arilla (2015), por sua vez, destacam outros subtipos de Turismo Gastronômico desenvolvidos a partir de azeites, queijos, carnes, peixes, trufas, frutas específicas e chocolate, dentre outras possibilidades.

$\mathrm{Na}$ literatura brasileira uma das definições de Turismo Gastronômico mais difundidas é a de Fagliari (2003, p.30-31), que apresenta o termo a partir de duas abordagens diferentes 6: "Para a demanda turística, consiste em toda viagem na qual a motivação principal está no prazer em degustar alimentos e bebidas e conhecer elementos gastronômicos de uma localidade. Para a oferta turística, o turismo gastronômico caracteriza-se pela oferta e promoção de elementos gastronômicos como atrativos turísticos principais do destino". Para Gândara, Gimenes \& Mascarenhas (2009, p.181), o turismo gastronômico pode ser compreendido como "[...] uma vertente do turismo cultural no qual o deslocamento de visitantes se dá por motivos vinculados às práticas gastronômicas de uma determinada localidade". Esta definição, inclusive, é a mencionada no manual "Turismo Cultural: orientações básicas" (Brasil, 2010). 0 enoturismo é definido por Valduga (2007, p. 16) como aquele que “[...] pressupõe deslocamento de pessoas, motivadas pelas propriedades organolépticas e por todo o contexto da degustação e elaboração de vinhos, bem como a apreciação das tradições, da cultura, gastronomia, das paisagens e tipicidades das regiões produtoras", tendo como ponto central o encontro entre visitantes e produtores.

As definições nacionais e estrangeiras descrevem o Turismo Gastronômico e o Enoturismo dando ênfase não apenas às experiências do comer e do beber, mas também às experiências culturais e de aprendizagem vivenciadas por meio das práticas alimentares e dos inúmeros atrativos que podem ser desenvolvidos a partir delas.

\subsection{Características e atrativos do Turismo Gastronômico}

Como observam Richards (2002), Boniface (2003), Hall \& Sharples (2003), Mitchell \& Hall (2003), Schlüter (2006) e Croce \& Perri (2010), os elementos gastronômicos são capazes de desenvolver turisticamente e contribuir para sua competitividade por serem reconhecidos como uma fonte identitária nas sociedades pósmodernas. O Turismo Gastronômico é desenvolvido sob a perspectiva de que as experiências gastronômicas "[...] can add value to tourism by providing the tourist with a link between local culture, landscape and food, and by creating the 'atmosphere' so essential to a memorable holiday experience" (HJALAGER; RICHARDS, 2002, p. 401), podendo estimular economias locais, fortalecer a sustentabilidade ambiental e cultural e a

\footnotetext{
6 A autora observa que esta divisão não é ideal, mas que é justificada por se tratar um segmento novo, e que nem sempre a localidade promovida como destino de turismo gastronômico é vista como tal pelos turistas, e vice e versa (FAGLIARI, 2005).
} 
inclusão social (UNWTO, 2017). O uso turístico de elementos gastronômicos, portanto, pode ganhar diferentes configurações e gerar diferentes efeitos em um destino, originando inúmeras possibilidades de leituras acadêmicas.

Schlüter (2006) destaca 3 principais categorias de atrativos gastronômicos: os cenários gastronômicos, as festas e os festivais, e as rotas gastronômicas. Os cenários gastronômicos são lugares de interação social a partir da comida e da bebida e são subdivididos entre públicos (restaurantes, etc.) e privados (refeitórios nos centros urbanos, etc.). As festas e festivais são acontecimentos programados com o protagonismo de elementos gastronômicos e se subdividem em ecofestas; teológicas; seculares e privadas. As rotas turísticas são iniciativas que "[...] permitem integrar em um produto os elementos que individualmente não atraem interesse suficiente ou contam com certas dificuldades de promoção ou comercialização, tornando possível um produto final de maior valor [...]" (Schlüter, 2006, p. 71) e podem ser organizadas em função de um produto ou um traço cultural característico.

\begin{tabular}{|c|c|c|}
\hline & Atrativo & Descritivo \\
\hline 1 & $\begin{array}{l}\text { Cursos e atividades } \\
\text { de aprendizado }\end{array}$ & $\begin{array}{l}\text { Cursos e atividades educativas com diferentes durações que ensinam sobre a pro- } \\
\text { dução e preparo de comidas ou bebidas. }\end{array}$ \\
\hline 2 & $\begin{array}{l}\text { Degustações e har- } \\
\text { monizações }\end{array}$ & $\begin{array}{l}\text { Degustações de diferentes produtos (azeite, chocolate, mel, queijo, vinho, cerveja, } \\
\text { cachaça, pratos típicos) que podem ser oferecidas em diferentes espaços e esta- } \\
\text { belecimentos. }\end{array}$ \\
\hline 3 & $\begin{array}{l}\text { Estabelecimentos } \\
\text { de alimentação }\end{array}$ & $\begin{array}{l}\text { Bares, restaurantes, casas noturnas, padarias e outros estabelecimentos de ali- } \\
\text { mentação fora do lar que, por alguma característica (localização, edificação, asso- } \\
\text { ciação a um filme ou livro, gastronomia diferenciada) são capazes de atrair visitan- } \\
\text { tes }\end{array}$ \\
\hline 4 & $\begin{array}{l}\text { Estabelecimentos } \\
\text { de comercialização } \\
\text { de produtos }\end{array}$ & $\begin{array}{l}\text { Locais dedicados à venda de produtos alimentícios (ingredientes ou produtos pron- } \\
\text { tos para consumo), tais como mercados municipais, adegas, lojas de chocolate, } \\
\text { etc. }\end{array}$ \\
\hline 5 & $\begin{array}{l}\text { Eventos gastronô- } \\
\text { micos }\end{array}$ & $\begin{array}{l}\text { Festas, festivais e outros eventos centrados em ingredientes in natura, em comi- } \\
\text { das ou bebidas específicas, ou tradições alimentares. Muitas vezes a programação } \\
\text { gastronômica é conjugada com opções de entretenimento. }\end{array}$ \\
\hline & $\begin{array}{l}\text { Feiras livres, feiras } \\
\text { gastronômicas e } \\
\text { comida de rua }\end{array}$ & $\begin{array}{l}\text { Feiras realizadas em espaços públicos para comercializar produtos in natura (fei- } \\
\text { ras livres) ou especializadas em comida e bebida pronta para consumo (feiras gas- } \\
\text { tronômicas). A menção à 'comida de rua' inclui barracas e foodtrucks em espaços } \\
\text { públicos que oferecem refeições ou petiscos prontos para consumo. }\end{array}$ \\
\hline 7 & Locais de produção & $\begin{array}{l}\text { Espaços de produção alimentar como queijarias, vinícolas, chocolaterias, alambi- } \\
\text { ques, etc., que ofereçam visitação. Esta categoria inclui estabelecimentos de "co- } \\
\text { lha e pague" e "pesque e pague". }\end{array}$ \\
\hline 8 & $\begin{array}{l}\text { Museus sobre ali- } \\
\text { mentação }\end{array}$ & $\begin{array}{l}\text { Instituições dedicadas a salvaguardar, conservar e exibir acervos relacionados a } \\
\text { diferentes práticas alimentares. }\end{array}$ \\
\hline 9 & $\begin{array}{l}\text { Comidas e bebidas } \\
\text { típicas }\end{array}$ & $\begin{array}{l}\text { Pratos, iguarias e bebidas tradicionais de uma localidade, oferecidos em eventos, } \\
\text { estabelecimentos de alimentação e em estabelecimentos de comercialização de } \\
\text { produtos }\end{array}$ \\
\hline 10 & $\begin{array}{l}\text { Rotas, roteiros e } \\
\text { circuitos turísticos }\end{array}$ & $\begin{array}{l}\text { Percursos previamente definidos que tenham temática abertamente gastronô- } \\
\text { mica, ou que possuam uma alta incidência de elementos gastronômicos, incluindo } \\
\text { diferentes atrativos mencionados neste quadro. }\end{array}$ \\
\hline
\end{tabular}

Fonte: a autora (2018)

Para Gândara et al. (2009), os principais atrativos gastronômicos são: culinária regional, eventos gastronômicos, estabelecimentos de alimentos e bebidas diferenciados, roteiros, rotas e circuitos gastronômicos. Já Fagliari (2005) destaca bares e restaurantes; pratos e produtos típicos; locais de produção; lojas e mercados; eventos; rotas gastronômicas; e outros elementos (escolas de culinária, museus, passeios de trem associados à degustação). Gimenes-Minasse (2017) amplia o quadro desenhado por Fagliari (2005), Schlüter (2006) e Gândara et al. (2009), identificando 8 categorias: estabelecimentos de alimentação fora do lar; pratos e produtos típicos; locais de produção alimentar; estabelecimentos de comercialização de produtos; feiras livres, feiras gastronômicas e comida de rua; eventos gastronômicos; 
roteiros, rotas e circuitos gastronômicos; além da categoria "outros" (museus sobre alimentação, escolas de culinária, espaços culturais com serviços de alimentação diferenciados, além de outros atrativos). 0 quadro 1 sintetiza os principais atrativos identificados:

Um destino pode desenvolver diferentes atrativos, fortalecendo sua oferta turística e atendendo diferentes expectativas relacionadas à gastronomia, tendo em vista que, como observam Hall \& Sharples ${ }^{7}$ (2003), visitantes podem possuir diferentes interesses relacionados às práticas alimentares. Contudo, observa-se que a complexidade do Turismo Gastronômico não se revela apenas em aspectos concernentes à oferta (tipologia e operacionalização de atrativos) mas também em dimensões que abrangem o planejamento e a gestão de regiões turísticas, bem como percepções e comportamentos da demanda.

\subsection{Apontamentos sobre o estudo do Turismo Gastronômico}

Barbosa \& Collaço (2018) afirmam que no Brasil estudos turísticos relacionados à gastronomia são recentes e ainda subdesenvolvidos se comparados com aqueles realizados na Inglaterra, França, Itália, Espanha e Portugal; mas estes estudos estão aumentando, o que, segundo os autores, indica o desenvolvimento deste subcampo de conhecimento. Esta perspectiva de campo em desenvolvimento também é sustentada por pesquisas de Hjalager \& Richards (2002), Scarpato (2002), Mitchell \& Hall (2003) e Kesimoglu (2015).

Em 2002 Hjalager \& Richards alertavam que as relações entre turismo e gastronomia, apesar de se darem na prática há muitos anos, eram um objeto de pesquisa recente. "In most established disciplines paradigms have been established, challenged and developed over long periods of time. In tourism and gastronomy, however, such structures are still relatively undeveloped" (Hjalager e Richards, 2002, p.227). Os autores ressaltam que se tratam de dois campos complexos, que envolvem uma gama de recursos e atores em suas composições, que trabalham com diferentes escalas de produção (desde a produção artesanal até a em massa) e são comumente associados a discussões sobre autenticidade.

Hjalager \& Richards (2002) e Scarpato (2002) reforçam a necessidade de pesquisas que desenvolvam abordagens multidisciplinares para o desenvolvimento dos estudos sobre turismo e gastronomia. Segundo Hjalager \& Richards (2002) a união das tradições de pesquisa destes dois campos tem o potencial de ampliar as perspectivas de produção de novos conhecimentos e que a divulgação do que já foi produzido/descoberto é fundamental neste processo, sendo necessário compreender as tensões geradas pela globalização alimentar e que o pesquisador se concentre mais no tipo de conhecimento que precisa ser desenvolvido do que no objeto em si. Como sugestão, indicam cinco perspectivas de pesquisa que precisam ser desenvolvidas para que uma visão holística do campo turismo-gastronomia possa ser construída:

Quadro 2 - Perspectivas de pesquisa em gastronomia e turismo
\begin{tabular}{|l|l|}
\hline Perspectiva & Características \\
\hline The Anecdotal & $\begin{array}{l}\text { Estudos de caso, construídos com diferentes técnicas de coleta de dados. Buscam descrever } \\
\text { uma realidade em suas características e especificidades. }\end{array}$ \\
\hline The Systematic & $\begin{array}{l}\text { Estudos que analisam um fenômeno de forma a organizá-lo em categorias descritivas ou ana- } \\
\text { líticas, tentando mapear o contexto, os resultados e as consequências associadas a ele. }\end{array}$ \\
\hline The Panoramic & $\begin{array}{l}\text { Estudos guiados por uma teoria. Os pesquisadores desejam fazer uma reconstrução histórica } \\
\text { ou interpretar uma realidade de acordo com uma perspectiva teórica específica. }\end{array}$ \\
\hline The Simultaneous & $\begin{array}{l}\text { Estudos que procuram suspender tempo e espaço na análise de fenômenos, utilizando técni- } \\
\text { cas de interpretação que criam um 'falso sincronismo' (como no estudo de tradições alimen- } \\
\text { tares no contexto contemporâneo). Esta abordagem geralmente suplementa as abordagens } \\
\text { citadas anteriormente. }\end{array}$ \\
\hline The Enactive & $\begin{array}{l}\text { Estudos que desejam alterar ou influenciar o objeto ou a realidade estudada, propondo reco- } \\
\text { mendações de intervenção. }\end{array}$ \\
\hline
\end{tabular}

Fonte: a autora, baseado em Hjalager \& Richards (2002)

\footnotetext{
7 Hall e Sharples (2003) estabelecem cinco categorias de interesse por gastronomia, variando desde o gourmet tourism e o gastronomic tourism (turistas que possuem um alto interesse em gastronomia e este orienta suas escolhas) até os turistas que possuem baixo ou nenhum interesse.
} 
Hjalager \& Richards (2002) tecem comentários sobre as limitações destas abordagens. Eles observam que muitos estudos de caso (the anecdotal perspective) são motivados pela admiração a uma determinada localidade e seus habitantes e tendem a privilegiar o que é considerado único e particular, fazendo análises muitas vezes subjetivas e românticas. E, embora esta abordagem seja comum e possa trazer informações importantes sobre questões específicas estabelecendo vínculos entre teoria e prática, precisam ser reavaliados e redimensionados, já que a realização de estudos isolados está ultrapassada. Os estudos de caso devem então assumir o poder de comparação ao serem integrados em estruturas de pesquisa mais abrangentes que possam influenciar o estabelecimento de uma nova teoria fundamentada. Em relação à abordagem "panoramic", os autores salientam que muitas vezes os pesquisadores tomam partido e perdem a objetividade ao analisar os dados coletados; sobre a abordagem "enactive" observam que muitas vezes os pesquisadores são recebidos com ceticismo pelos diferentes atores envolvidos na realidade que pretendem estudar, o que dificulta a tarefa de lidar com problemas reais.

A tendência ao foco excessivo, com a perda do contexto pesquisado, também é observada por outros autores. Analisando um conjunto de pesquisas publicadas em língua inglesa, Kesimoglu (2015) observa que muitas se concentram em aspectos fragmentados. A gastronomia é frequentemente reduzida a um mero objeto de valor promocional ou de vantagem competitiva associada a outros segmentos turísticos, se fixando nos benefícios financeiros gerados por ela, desconsiderando a perspectiva cultural e simbólica. Outros trabalhos, segundo o autor, assumem a gastronomia como patrimônio cultural, embora não considerem o contexto cultural mais amplo nem analisem criticamente como se dá essa apropriação turística. Kesimoglu (2015) destaca outra abordagem recorrente: aquela que analisa o potencial gastronômico de destinações e oferece soluções para melhorar a realidade atual, ou ainda indica quais são os fatores fundamentais para o sucesso de uma localidade neste segmento. Esta visão tende a consolidar a ideia de que todo lugar com patrimônio gastronômico pode se tornar um centro gastronômico, desde que sejam replicadas metodologias observadas em casos de sucesso, mesmo que pertencentes a contextos regionais diferentes.

Ao analisarem pesquisas sobre gastronomia e turismo, Mitchell \& Hall (2003) constatam que muitos estudos se limitam a questões de segurança e higiene, à análise do público de eventos gastronômicos, à produção alimentar no contexto do turismo; à promoção cruzada entre a gastronomia e o turismo e os impactos do turismo em cozinhas regionais ou nacionais. Para os autores, uma lacuna importante reside nos estudos voltados para as experiências de consumo que possam orientar decisões de proprietários e gerentes de cafés, restaurantes, meios de hospedagem, escolas de culinária, produtores de alimentos e organizadores de eventos.

Para Scarpato (2002) é preciso que as pesquisas unindo turismo e gastronomia sejam desenvolvidas de forma transdisciplinar, que estejam envolvidas no planejamento e operacionalização de ações relacionadas ao turismo gastronômico e que possam contribuir para a requalificação da gestão gastronômica de estabelecimentos turísticos gastronômicos por meio de abordagens criativas. Neste processo, Scapato (2002) destaca ainda a importância da incorporação de terminologias da área de gastronomia (por considerar que o turismo sempre lidou de forma superficial com os conceitos relacionados à gastronomia); do entendimento da gastronomia em seu contexto cultural (para sua compreensão como fonte de experiência cultural turística); e do estudo da sustentabilidade aplicada à gastronomia e ao turismo.

\section{PROCEDIMENTOS METODOLÓGICOS}

Santos \& Rejowski (2013) argumentam que os periódicos constituem o principal meio formal de comunicação científica, caracterizando-se com uma fonte de informação escrita pré-avaliada em uma determinada área ou campo de conhecimento, editada periodicamente por tempo indeterminado, contando com uma política editorial definida e a colaboração de vários pesquisadores. Gonçalves, Ramos \& Castro (2006) ressaltam ainda o papel fundamental dos periódicos na avaliação da produção científica de pesquisadores, notadamente em Programas de Pós-graduação stricto sensu (PPG).

No Brasil, embora possam ser encontradas diversas pesquisas que abordam a produção científica das áreas de turismo e hospitalidade no plano geral, como Santos \& Rejowski (2012) e Bastos \& Rejowski (2015), há poucas iniciativas voltadas para o estudo da produção científica sobre o tema gastronomia no contexto do turismo. Destacam-se as recentes publicações de Barbosa \& Collaço (2018) e de Ribeiro-Martins \& Silveira- 
Martins (2018) sobre Turismo Gastronômico, e a de Ferro \& Rejowski (2018) sobre a produção científica sobre gastronomia no Brasil.

Ferro \& Rejowski (2018) estudaram 223 dissertações e teses produzidas no Brasil sobre gastronomia em diferentes PPG, analisando o ano de defesa, áreas de conhecimento e, a partir de seus títulos, resumos e palavras-chave, as principais temáticas trabalhadas. Embora não seja uma pesquisa específica sobre o binômio turismo-gastronomia, algumas temáticas identificadas abrigam trabalhos relacionados à gastronomia e turismo, como 'identidade e patrimônio', 'gastronomia como atrativo', 'locais de manifestações gastronômicas' e 'conglomerados turísticos gastronômicos'. Barbosa \& Collaço (2018) analisaram a produção de pesquisadores brasileiros sobre turismo e gastronomia entre 2007 e 2016 em 24 periódicos nacionais e estrangeiros. Identificaram 78 artigos a partir dos termos comer, cozinha, culinária, comida, gastronomia, restaurante e tour, que foram analisados por ano de publicação, distribuição por periódico, autores mais frequentes e suas respectivas formações, tipo de pesquisa realizada, perspectivas teóricas desenvolvidas e ocorrência de palavras-chave. Já Ribeiro-Martins \& Silveira-Martins (2018) realizaram um estudo bibliométrico a partir das bases Periódicos CAPES, PROQUEST, EBSCO e SPELL com termos de busca Turismo Gastronômico, Gastronomic Tourism e Turismo Gastronómico (Food Tourism não foi considerado). Analisaram 45 artigos publicados em 27 periódicos de diferentes nacionalidades, considerando a distribuição por revistas, evolução temporal, tipos de metodologia, autores e trabalhos com maior número de referência.

Internacionalmente, além já mencionada contribuição de Hjalager \& Richards (2002) sobre a pesquisa em turismo gastronômico, destaca-se o trabalho de Okumus, Koseoglu \& Ma (2018), uma análise bibliográfica de 462 artigos publicados em 16 periódicos internacionais entre 1976 e 2016 que considerou a distribuição dos artigos por ano, periódico, temática, abordagem metodológica, artigos publicados por autor, principais autores e instituições envolvidas. Tendo em vista a proximidade entre as pesquisas, será possível estabelecer análises comparativas na apresentação e discussão dos resultados encontrados nesta iniciativa.

Considerando o objetivo deste trabalho, optou-se por analisar publicações com estrato Qualis igual ou superior a B5 identificadas pelo website Qualis Periódico pelos termos: turismo, tourism, hospitalidade e hospitality (alguns periódicos brasileiros adotam títulos em inglês). Foram identificados 25 periódicos nacionais.

Os websites destes periódicos foram consultados com os termos de busca: alimentação, alimento, bebida, culinária, enoturismo, gastronomia, restaurante, turismo cervejeiro, turismo gastronômico e prato típico (termos indicados em ordem alfabética). Foram consideradas apenas publicações de pesquisadores brasileiros ou de outras nacionalidades que realizam suas atividades de pesquisa no Brasil; foram excluídas as resenhas e editoriais. Os títulos, resumos e palavras-chave foram analisados para identificar se o turismo gastronômico era o objeto de investigação central. Como resultado, foram identificados 89 artigos válidos, publicados em 16 periódicos. O primeiro artigo válido foi publicado em 2005, o que definiu a janela cronológica de análise entre 2005 e 2017.

Os artigos selecionados foram organizados em uma planilha Excel, com seu título, autores, resumo e palavras-chaves identificados. A identificação e análise das temáticas e subtemáticas foi realizada seguindo os parâmetros da análise de conteúdo baseada em Bardin (2011), com a construção de categorias a posteriori, delineadas a partir da aproximação. Foram identificadas 8 temáticas e 11 subtemáticas que serão apresentadas oportunamente. Tendo em vista as lacunas percebidas nos resumos, a análise dos procedimentos metodológicos exigiu a leitura dos textos integrais. Os websites dos periódicos também foram consultados para identificar a instituição responsável e o ano da primeira edição. Foi realizada ainda uma consulta à base de Currículos Lattes do CNPq para identificar o perfil de formação dos autores que publicaram dois ou mais artigos válidos. Todos os levantamentos foram realizados entre os meses de março e junho de 2018. Os dados foram organizados em figuras, gráficos, quadros sínteses e tabelas. 


\section{APRESENTAÇÃO E DISCUSSÃO DOS RESULTADOS}

Dos 25 periódicos inicialmente identificados, 16 (64\%) publicaram ao menos um artigo sobre Turismo Gastronômico, como evidenciado no quadro 3:

\begin{tabular}{|c|c|c|c|c|c|}
\hline & Periódico/Revista & Instituições responsáveis & Início & Qualis & $\begin{array}{l}\text { Total arti- } \\
\text { gos }\end{array}$ \\
\hline 1 & Turismo em Análise & Univ. de São Paulo (USP) & 1990 & B1 & 12 \\
\hline 2 & Turismo: Visão e Ação & Univ. do Vale do Itajaí (UNIVALI) & 1998 & B1 & 8 \\
\hline 3 & Caderno Virtual de Turismo -CVT & Univ. Federal do Rio de Janeiro (UFRJ) & 2001 & B1 & 2 \\
\hline 4 & Hospitalidade & Univ. Anhembi Morumbi (UAM) & 2004 & B3 & 6 \\
\hline 5 & $\begin{array}{l}\text { Cultur - Revista de Cultura e Tu- } \\
\text { rismo }\end{array}$ & Univ. Estadual de Santa Cruz (UESC) & 2007 & B5 & 4 \\
\hline 6 & $\begin{array}{l}\text { Brasileira de Pesquisa em Tu- } \\
\text { rismo - RBTUR }\end{array}$ & $\begin{array}{l}\text { Associação Nacional de Pesquisa e } \\
\text { Pós-Graduação em Turismo (ANPTUR) }\end{array}$ & 2007 & A2 & 4 \\
\hline 7 & Turismo e Sociedade & Univ. Federal do Paraná (UFPR) & 2008 & B4 & 11 \\
\hline 8 & Brasileira de Ecoturismo & $\begin{array}{l}\text { Sociedade Brasileira de Ecoturismo } \\
\text { (SBEcotur) }\end{array}$ & 2008 & B3 & 3 \\
\hline 9 & Rosa dos Ventos & Univ. Caxias do Sul (UCS) & 2009 & B2 & 16 \\
\hline 10 & $\begin{array}{l}\text { Anais Brasileiros de Estudos Tu- } \\
\text { rísticos - ABET }\end{array}$ & Univ. Federal de Juiz de Fora (UFJF) & 2011 & B3 & 2 \\
\hline 11 & $\begin{array}{l}\text { Iberoamericana de Turismo - RI- } \\
\text { TUR }\end{array}$ & $\begin{array}{l}\text { Univ. Federal de Alagoas (UFAL) e Uni- } \\
\text { versidad et Girona (UdG) }\end{array}$ & 2011 & B3 & 2 \\
\hline 12 & $\begin{array}{l}\text { Eletrônica de Administração e } \\
\text { Turismo - ReAT }\end{array}$ & $\begin{array}{llll}\begin{array}{l}\text { Universidade } \\
\text { (UFPel) }\end{array} & \text { Federal de } & \text { Pelotas } \\
\text { (UFel } & & \end{array}$ & 2012 & B3 & 1 \\
\hline 13 & Turismo: Estudos e Práticas & $\begin{array}{l}\text { Univ. Estadual do Rio Grande do Norte } \\
\text { (UERN) }\end{array}$ & 2012 & B4 & 3 \\
\hline 14 & $\begin{array}{l}\text { Caderno de Estudos e Pesqui- } \\
\text { sas em Turismo }\end{array}$ & $\begin{array}{l}\text { Pontifícia Universidade Católica do Pa- } \\
\text { raná (PUC PR) }\end{array}$ & 2012 & B4 & 5 \\
\hline 15 & R. de Turismo Contemporâneo & $\begin{array}{l}\text { Univ. Federal do Rio Grande do Norte } \\
\text { (UFRN) }\end{array}$ & 2013 & B3 & 6 \\
\hline 16 & Applied Tourism & Univ. do Vale do Itajaí (UNIVALI) & 2016 & B5 & 4 \\
\hline
\end{tabular}

Fonte: a autora (2018)

Verifica-se que os periódicos apresentam diferentes graus de maturidade. 0 mais longevo é a Revista Turismo em Análise, mantida pela USP desde 1990, seguida pela Turismo: Visão e Ação, criada pela Univali oito anos depois. Os demais foram criados a partir de 2001, sendo a Applied Tourism a mais jovem, tendo sua primeira publicação em 2016 . Sete $(43,75 \%)$ são mantidos por IES que possuem PPG nas áreas de Turismo e Hospitalidade, 2 (12,5\%) são mantidos por entidades de pesquisa (ANPTUR e SBEcotur) e os demais (43,75\%) são publicados por IES sem PPG na área. Considerando as avaliações QUALIS (2018) obtidas, tem-se que a maioria dos periódicos se concentra no estrato B3 (6 periódicos, 37,5\%) seguido pelos estratos B1 e B4 (cada um com 3 periódicos, equivalendo a 18,75\%). Há apenas 1 periódico no estrato A2 (6,25\%). 0 gráfico 1 apresenta a distribuição de artigos por estrato QUALIS (2018): 


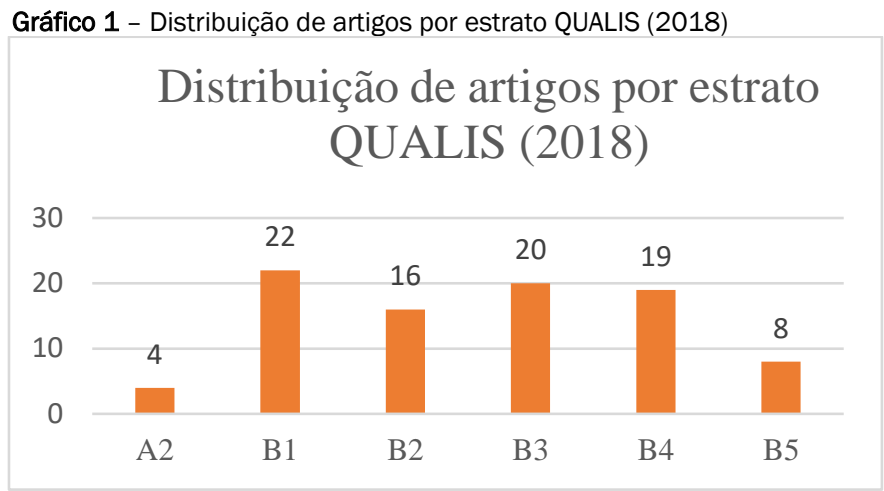

Fonte: a autora (2018)

A maior parcela dos artigos foi publicada em periódicos de estrato B1 (22 artigos, 24,71\%), um bom indicativo de qualidade, embora este número seja superado pela somatória das publicações em revistas B4 (19 artigos ou 21,34\%) e B5 (8 artigos ou 8,98\%). 0 estrato B3 totalizou 20 artigos (22,47\%) e apenas 4 artigos $(4,49 \%)$ foram publicados no único periódico pertencente ao estrato A2. 0 gráfico 2 considera a distribuição de artigos por periódico:

Gráfico 2 - Número de artigos publicados por periódico

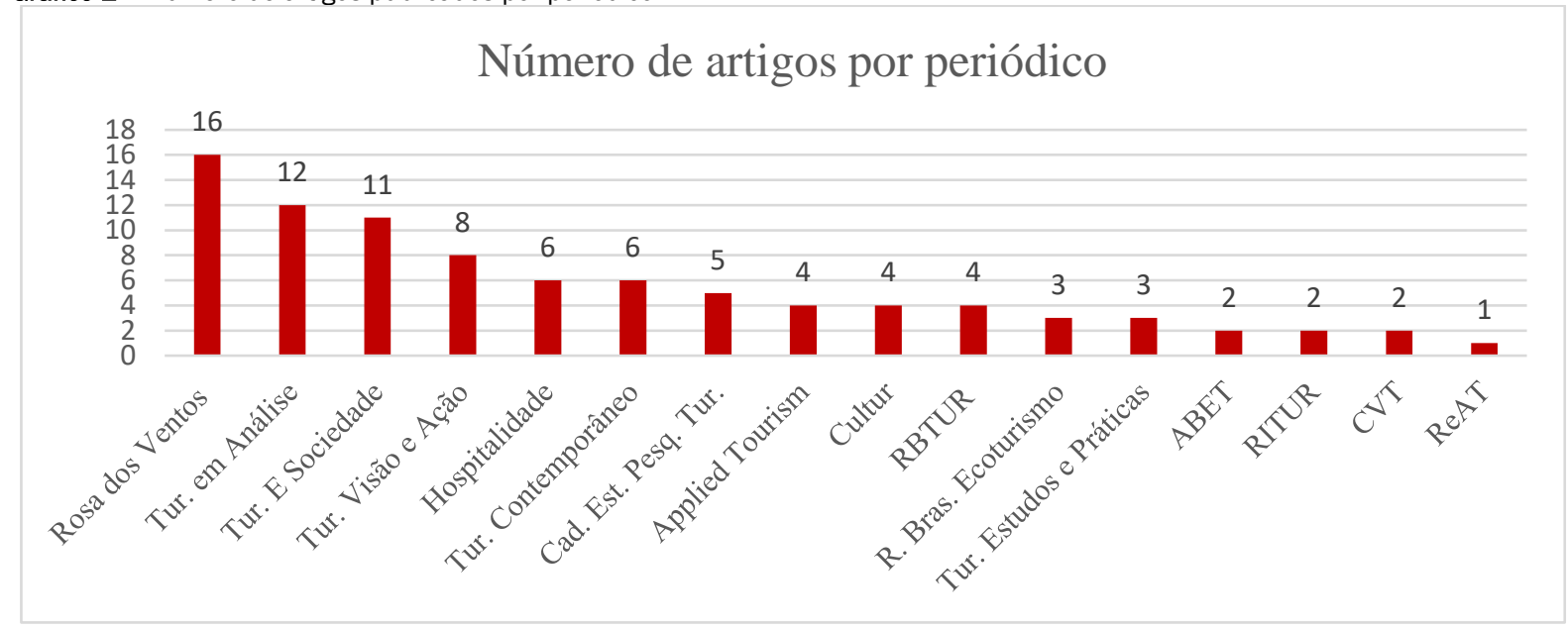

Fonte: a autora (2018)

A Revista Rosa dos Ventos foi a mais receptiva ao tema, publicando o maior número de artigos (16 artigos, 17,97\%), seguida pela Turismo em Análise (12 artigos, 13,38\%). No levantamento realizado por RibeiroMartins \& Silveira-Martins (2018) e por Barbosa \& Collaço (2018) a Rosa dos Ventos também é o periódico com o maior número de publicações. A análise de Okumus et al. (2018) se baseou apenas em periódicos internacionais. Três periódicos ${ }^{8}$ desenvolveram dossiês temáticos: a Rosa dos Ventos publicou duas edições do Dossiê Gastronomia e Turismo em 2012 e em 2013; a Turismo e Sociedade lançou em 2014 um número especial sobre Enoturismo9; e a Turismo Estudos e Práticas publicou o Dossiê Turismo e Gastronomia em 2017. Observa-se que a chamada de artigos realizada pela Rosa dos Ventos em 2012 previa a publicação de um único número, mas a boa resposta dos autores permitiu o desdobramento em duas edições (GimenesMinasse \& Peccini, 2012). Estes números especiais evidenciam o reconhecimento do tema no âmbito

\footnotetext{
8 A Revista Cultur publicou em 2015 um número especial sobre enoturismo apresentando os artigos em francês apresentados durante o Colóquio Internacional Vinho, Patrimônio, Turismo e Desenvolvimento realizado em 2013 pela Cátedra UNESCO Cultura e Tradições do Vinho da Universidade da Borgonha, Cátedra UNESCO Cultura, Turismo, Desenvolvimento, da Universidade Paris I PanthéonSorbonne e UFPR.

9 O número reuniu artigos em português apresentados durante o Colóquio Internacional Vinho, Patrimônio, Turismo e Desenvolvimento realizado em 2013 pela Cátedra UNESCO Cultura e Tradições do Vinho da Universidade da Borgonha, Cátedra UNESCO Cultura, Turismo, Desenvolvimento, da Universidade Paris I Panthéon-Sorbonne e UFPR.
} 
acadêmico do turismo e a existência de pesquisadores capazes de atender a estas convocatórias cumprindo as exigências de cada periódico.

A tabela 1 apresenta a distribuição de artigos por periódico e ano de publicação (os anos que não foram incluídos não tiveram artigos válidos):

Tabela 1 - Distribuição de artigos por periódico e por ano

\begin{tabular}{llllllllllll}
\hline Periódico & 2005 & $\mathbf{2 0 0 9}$ & $\mathbf{2 0 1}$ & $\mathbf{2 0 1}$ & $\mathbf{2 0 1}$ & $\mathbf{2 0 1}$ & $\mathbf{2 0 1}$ & $\mathbf{2 0 1}$ & $\mathbf{2 0 1}$ & $\mathbf{2 0 1}$ & Total (\%) \\
& & & $\mathbf{0}$ & $\mathbf{1}$ & $\mathbf{2}$ & $\mathbf{3}$ & $\mathbf{4}$ & $\mathbf{5}$ & $\mathbf{6}$ & $\mathbf{7}$ & \\
\hline Rosa dos Ventos & - & - & 1 & - & 4 & 6 & 1 & 3 & 1 & - & $16(17,97 \%)$ \\
Turismo em Análise & 1 & 2 & 1 & 2 & 3 & - & - & - & 1 & 2 & $12(13,38 \%)$ \\
Turismo e Soc. & - & 1 & - & - & 1 & - & 7 & - & 1 & 1 & $11(12,30 \%)$ \\
Tur.: Visão e Ação & - & - & - & 3 & 1 & - & - & - & 3 & 1 & $8(8,98 \%)$ \\
R. Hospitalidade & - & - & - & 1 & 1 & 1 & - & 1 & 2 & - & $6(6,70 \%)$ \\
R. Tur. Contemp. & - & - & - & - & - & - & 1 & 2 & 1 & 2 & $6(6,70 \%)$ \\
Cad. Est. Pesq. Tur. & - & - & - & - & - & - & - & 2 & 2 & 1 & $5(5,60 \%)$ \\
Applied Tourism & - & - & - & - & - & - & - & - & 3 & 1 & $4(4,49 \%)$ \\
CULTUR & - & - & - & - & - & - & - & 3 & - & 1 & $4(4,49 \%)$ \\
RBTUR & - & 1 & - & - & 2 & - & - & - & - & 1 & $4(4,49 \%)$ \\
R. Bras. Ecoturismo & - & - & - & 1 & 1 & - & - & - & - & 1 & $3(3,30 \%)$ \\
R. Tur: Estudos & - & - & - & - & - & - & 1 & - & - & 2 & $3(3,30 \%)$ \\
Práticas & & & & & & & & & & & $2(2,40 \%)$ \\
ABET & - & - & - & - & - & - & 1 & 1 & - & - & $2(2,40 \%)$ \\
RITUR & - & - & - & - & - & - & - & 1 & - & 1 & $2(2,40 \%)$ \\
CVT & - & - & - & - & - & - & 1 & - & - & 1 & $2(2,10 \%)$ \\
ReAT & - & - & - & - & - & - & - & 1 & - & - & $1(1,10 \%)$ \\
Total de artigos & 1 & 4 & 2 & 7 & 13 & 7 & 12 & 14 & 14 & 15 & 89 \\
\% & 1,10 & 4,49 & 2,40 & 7,86 & 14,5 & 7,85 & 13,4 & 15,7 & 15,7 & 16,8 & $100 \%$ \\
& & & & & & & 7 & & & 4 &
\end{tabular}

Fonte: a autora (2018)

O gráfico 3 permite visualizar o volume de artigos publicados por ano:

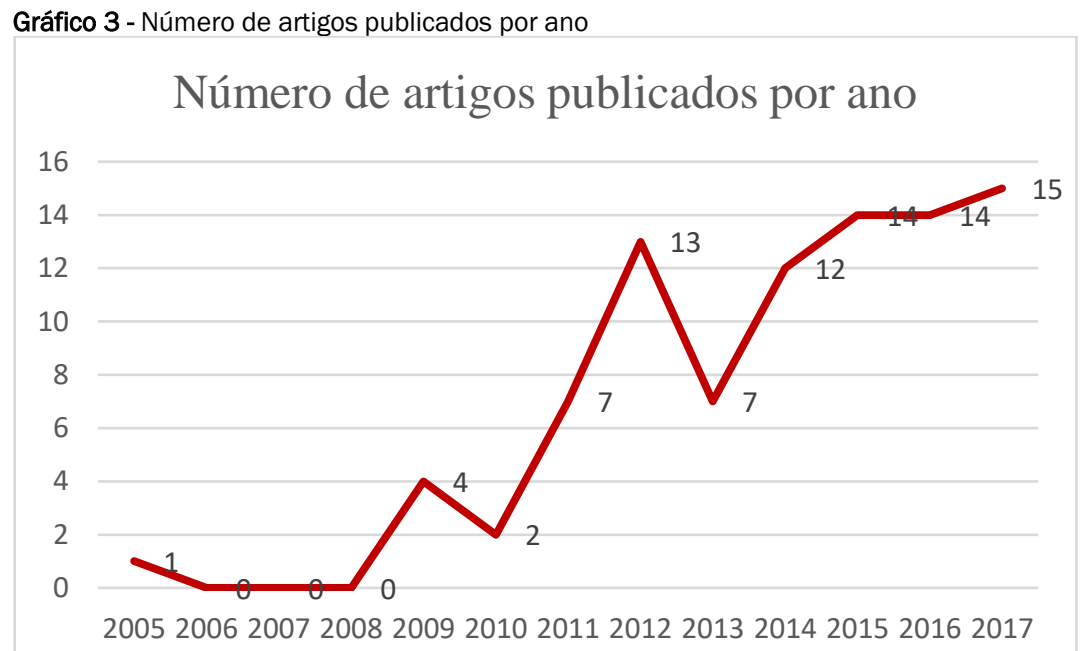

Fonte: a autora (2018)

A tabela 1 e gráfico 3 mostram que, embora a pesquisa tenha abrangido todo o ciclo de vida dos periódicos, o primeiro artigo centrado no Turismo Gastronômico foi publicado apenas em 2005 pela Turismo em Análise. Deve-se mencionar que em 2003 foi publicado no Brasil o primeiro livro dedicado ao binômio turismogastronomia, “Turismo e Gastronomia”, da pesquisadora argentina Regina Schlüter. 0 ano de 2005 também marca o lançamento do primeiro livro específico de um autor brasileiro sobre o tema, "Turismo e Alimentação", de Gabriela Fagliari. 
A partir de 2005 constatou-se um hiato, encerrado em 2009, com a publicação de 4 artigos. Após o pico de 13 publicações em 2012, apenas 7 artigos foram publicados em 2013. Em 2014 foram 12 artigos e em 2015 e 2016, 14 artigos. 0 ápice foi 2017, com 15 artigos. Verifica-se uma constância de publicações nos quatro últimos anos, totalizando 55 artigos (61,79\%). Lembra-se que a publicação de dossiês/números especiais explica concentração de publicações nos anos 2012, 2013, 2014 e 2017.

Em 2016 e 2017 houve uma maior distribuição de artigos entre os periódicos, envolvendo, respectivamente, 8 e 12 revistas, evidenciando uma maior abertura para a temática. Destaca-se que a Turismo em Análise, o mais longevo periódico, é a que apresenta uma distribuição mais homogênea de artigos ao longo da janela cronológica estudada.

Observa-se que Okumus et al. (2018), que estudaram o cenário internacional de publicações sobre alimentação e gastronomia associada ao turismo e à hospitalidade em uma janela cronológica iniciada em 1976, indicam um aumento de artigos sobre estas temáticas a partir do ano 2000, tendo como ápice 2016, ano em que se encerra o levantamento realizado. Estes autores, contudo, consideram que este aumento não é muito expressivo. Ribeiro-Martins \& Silveira-Martins (2018), que estudaram periódicos nacionais e estrangeiros, identificaram o ano de 2012 como sendo o de maior concentração de artigos em seu levantamento. Já Barbosa e Collaço (2018), que também estudaram periódicos nacionais e estrangeiros, mas se preocupando apenas com pesquisadores brasileiros, encontraram no ano de 2014 o maior número de publicações. Observa-se, em todos os casos, que a temática parece ganhar força a partir de 2012.

A partir de uma análise de conteúdo categorial dos títulos, resumos e palavras-chave, pode-se identificar 8 temáticas e 11 subtemáticas, apresentadas na figura 1:

Figura 1 - Temáticas e subtemáticas identificadas nos artigos analisados

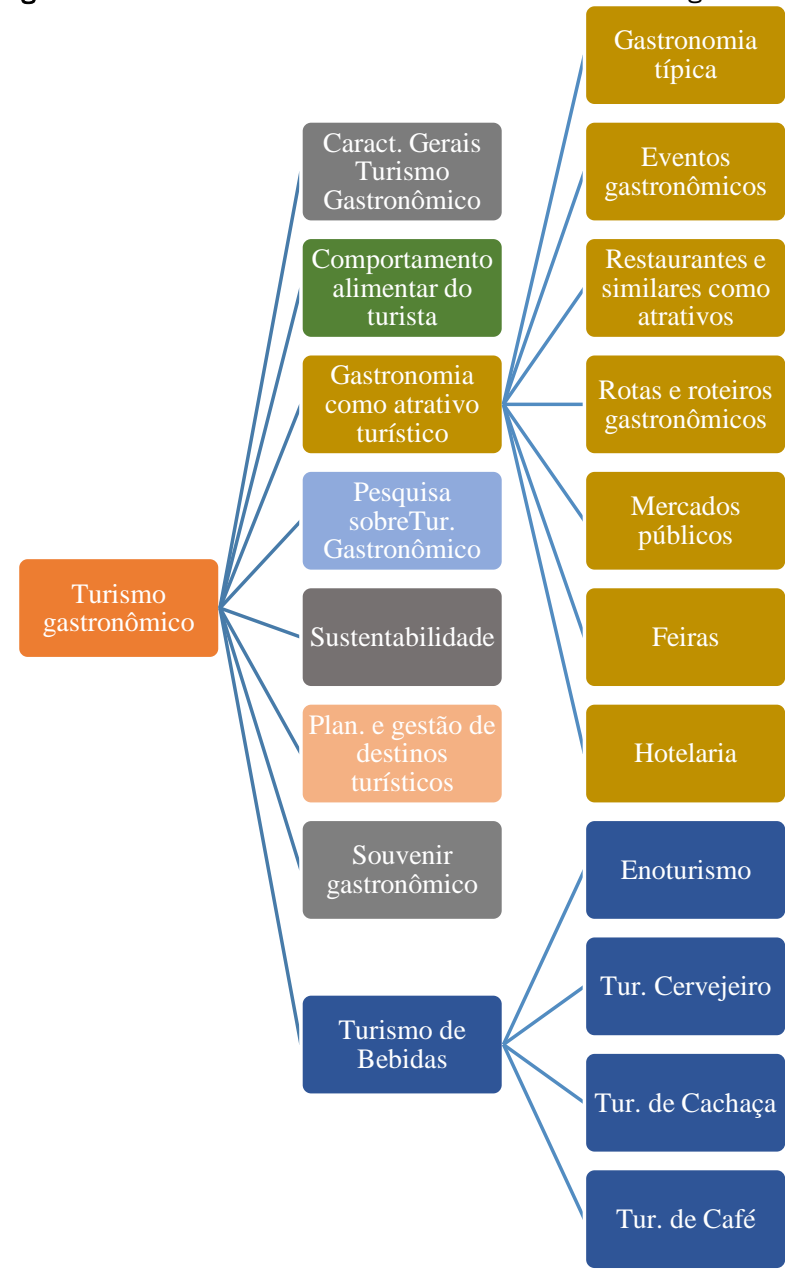

Fonte: a autora (2018) 
O quadro 4 sintetiza o conteúdo das temáticas encontradas:

Quadro 4- Temáticas abordadas nos artigos analisados

\begin{tabular}{|c|c|c|}
\hline & Temática & Descritivo dos artigos pertencentes a esta temática \\
\hline 1 & $\begin{array}{l}\text { Características gerais do Turismo Gas- } \\
\text { tronômico }\end{array}$ & $\begin{array}{l}\text { Discutem conceitos e características gerais do Turismo Gastronô- } \\
\text { mico }\end{array}$ \\
\hline 3 & Gastronomia como atrativo turístico & $\begin{array}{l}\text { Tratam da operacionalização de elementos gastronômicos (inclu- } \\
\text { indo iguarias, práticas alimentares e serviços de alimentação) } \\
\text { como atrativos turísticos }\end{array}$ \\
\hline 4 & Pesquisa sobre Turismo Gastronômico & $\begin{array}{l}\text { Analisa o estudo do Turismo Gastronômico a partir de uma corrente } \\
\text { metodológica }\end{array}$ \\
\hline 5 & Sustentabilidade & $\begin{array}{l}\text { Discutem a sustentabilidade em restaurantes e/ou eventos gastro- } \\
\text { nômicos no contexto do turismo }\end{array}$ \\
\hline 8 & Turismo de Bebidas & $\begin{array}{l}\text { Analisam o planejamento e a operacionalização de iniciativas as- } \\
\text { sociadas ao Turismo de Bebidas }\end{array}$ \\
\hline
\end{tabular}

Fonte: a autora (2018)

Devido à diversidade de abordagens duas temáticas, Gastronomia como atrativo turístico (GAT) e Turismo de Bebidas (TB) puderam ser divididas em subtemáticas, apresentadas no quadro 5:

\begin{tabular}{|c|c|c|}
\hline Temática & Subtemáticas & Descritivo dos artigos incluídos nas subtemáticas \\
\hline \multirow[t]{7}{*}{$\begin{array}{l}\text { Gastronomia como } \\
\text { atrativo turístico }\end{array}$} & Gastronomia típica & $\begin{array}{l}\text { Tratam do uso de iguarias tradicionais como atrativo turís- } \\
\text { tico }\end{array}$ \\
\hline & Eventos gastronômicos & $\begin{array}{l}\text { Abordam o planejamento e a operacionalização de eventos } \\
\text { gastronômicos }\end{array}$ \\
\hline & $\begin{array}{l}\text { Restaurantes e similares } \\
\text { como atrativos }\end{array}$ & $\begin{array}{l}\text { Tratam de restaurantes e similares como atrativos turísti- } \\
\text { cos }\end{array}$ \\
\hline & $\begin{array}{l}\text { Rotas e roteiros gastronômi- } \\
\text { cos }\end{array}$ & $\begin{array}{l}\text { Analisam a operacionalização e gestão de rotas e roteiros } \\
\text { gastronômicos }\end{array}$ \\
\hline & Mercados públicos & Abordam mercados públicos como atrativos turísticos \\
\hline & Feiras & Aborda uma feira gastronômica como atrativo turísico \\
\hline & Hotelaria & $\begin{array}{l}\text { Analisa a oferta gastronômica de um meio de hospedagem } \\
\text { como atrativo turístico }\end{array}$ \\
\hline \multirow[t]{4}{*}{ Turismo de bebidas } & Enoturismo & $\begin{array}{l}\text { Tratam do planejamento e da operacionalização de regiões } \\
\text { enoturísticas, incluindo a análise de atrativos turísticos vin- } \\
\text { culados a este subsegmento }\end{array}$ \\
\hline & Turismo Cervejeiro & Abordam de atrativos relacionados ao Turismo Cervejeiro \\
\hline & Turismo de Cachaça & Tratam de atrativos relacionados ao Turismo de Cachaça \\
\hline & Turismo de Café & $\begin{array}{l}\text { Analisa o potencial do Turismo do Café em uma região bra- } \\
\text { sileira }\end{array}$ \\
\hline
\end{tabular}

Fonte: a autora (2018)

Os quadros 4 e 5 evidenciam os diferentes elementos envolvidos no planejamento e desenvolvimento do Turismo Gastronômico e a diversidade de subtemáticas estudadas. Considerando a distribuição de artigos por temáticas e subtemáticas, tem-se a predominância da temática Gastronomia como Atrativo Turístico (36 artigos ou 40,45\%) seguida por Turismo de Bebidas (30 artigos, 33,70\%), como observado no gráfico 4: 


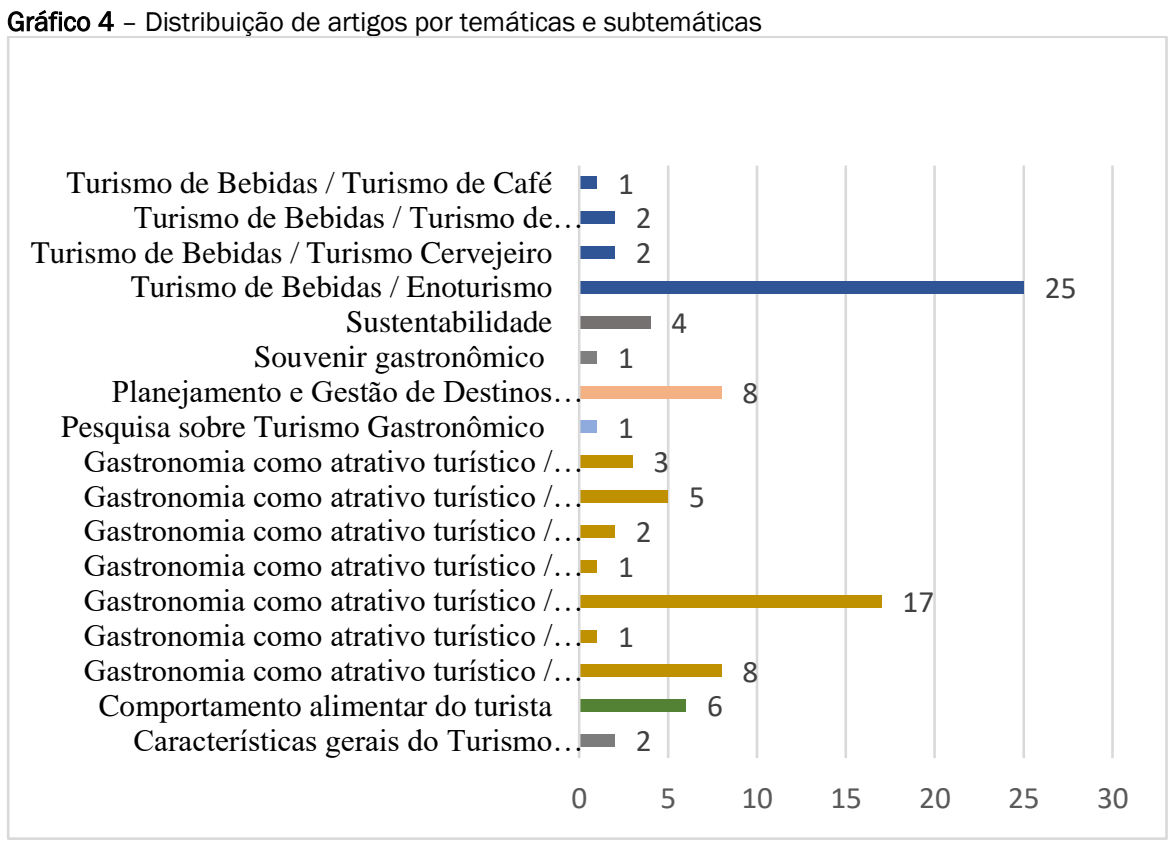

Fonte: a autora (2018)

Turismo de Bebidas/Enoturismo se destaca, correspondendo a $28,09 \%$ de todos os artigos publicados, seguido por Gastronomia como atrativo turístico/Gastronomia típica, que corresponde a $19,1 \%$. Na sequência, tem-se Planejamento e Gestão de Destinos Turísticos e Gastronomia como atrativo turístico/Evento gastronômico (8,89\%). Observa-se que a temática dos artigos não foi objeto de análise de Ribeiro-Martins e Silveira-Martins (2018) nem de Barbosa e Collaço (2018), e no estudo promovido por Okumus et al. (2018) não há correspondências, já que estes autores identificam "Food Tourism" como uma categoria única, que corresponde a $28,35 \%$ dos artigos analisados ${ }^{10}$.

No corpus de análise Turismo de Bebidas/Turismo de café, Souvenir gastronômico, Pesquisa sobre Turismo Gastronômico, Gastronomia como atrativo turístico/Hotelaria e Gastronomia como atrativo turístico/Feiras são as temáticas/subtemáticas menos desenvolvidas, com apenas 1 artigo. Turismo de Bebidas/Turismo de Cachaça, Turismo de Bebidas/Turismo Cervejeiro, Gastronomia como atrativo turístico/Mercados públicos e Características gerais do Turismo Gastronômico contaram com apenas 2 artigos. Procurando perceber tendências relacionadas às temáticas e subtemáticas durante o recorte cronológico estudado, foi elaborada a tabela 2.

A temática TB/Enoturismo, que inaugurou a janela cronológica em 2005, é a que foi publicada de forma mais consistente, não tendo artigos apenas nos anos 2006, 2007 e 2008 (período no qual nenhum artigo relacionado ao Turismo Gastronômico foi identificado). 0 ápice desta temática foi em 2014, quando um dossiê temático foi publicado. GAT/Gastronomia típica também merece destaque, sendo objeto de publicações por sete anos. Considerando os quatro últimos anos da janela cronológica, a temática com maior incidência é TB/Enoturismo com 15 artigos, 11 abordando o desenvolvimento regional do enoturismo em estados como Bahia, Paraná, Pernambuco, Santa Catarina e, predominantemente, Rio Grande do Sul; e 4 a operacionalização de vinícolas neste contexto. GAT/Gastronomia típica conta com 11 artigos tratando do uso turístico de iguarias tradicionais no contexto do turismo. Planejamento e Gestão de Destinos Turísticos contam com 6 artigos; e GAT/Eventos gastronômicos e GAT/Restaurantes e similares com 4 artigos. Dentre as temáticas trabalhadas apenas nos anos mais recentes, podendo ser consideradas novas temáticas/subtemáticas tem-se o souvenir gastronômico (com uma publicação em 2017) e TB/Turismo cervejeiro (publicações em 2016 e 2017).

\footnotetext{
10 Outras categorias são: Ciência dos alimentos, Alimentação e saúde, Alimentação e operações culinárias, Alimentação e cultura, Segurança alimentar, Oferta de alimentos, e Alimentação e educação.
} 


\begin{tabular}{|c|c|c|c|c|c|c|c|c|c|c|c|}
\hline Temática/Subtemática & $\begin{array}{l}200 \\
5\end{array}$ & $\begin{array}{l}200 \\
9\end{array}$ & $\begin{array}{l}201 \\
0\end{array}$ & $\begin{array}{l}201 \\
1\end{array}$ & $\begin{array}{l}201 \\
2\end{array}$ & $\begin{array}{l}201 \\
3\end{array}$ & $\begin{array}{l}201 \\
4\end{array}$ & $\begin{array}{l}201 \\
5\end{array}$ & $\begin{array}{l}201 \\
6\end{array}$ & $\begin{array}{l}201 \\
7\end{array}$ & $\begin{array}{l}\text { Total } \\
(\%)\end{array}$ \\
\hline $\begin{array}{l}\text { C. gerais Tur. Gastronô- } \\
\text { mico }\end{array}$ & 0 & 0 & 0 & 0 & 1 & 0 & 1 & 0 & 0 & 0 & $\begin{array}{l}2 \\
2,24 \%\end{array}$ \\
\hline $\begin{array}{l}\text { Comportamento alimen- } \\
\text { tar do turista }\end{array}$ & 0 & 0 & 0 & 2 & 1 & 0 & 1 & 1 & 0 & 1 & $\begin{array}{l}6 \\
6,76 \%\end{array}$ \\
\hline $\begin{array}{l}\text { GAT/ Evento gastronô- } \\
\text { mico }\end{array}$ & 0 & 0 & 0 & 0 & 2 & 2 & 0 & 1 & 1 & 2 & $\begin{array}{l}8 \\
8,99 \%\end{array}$ \\
\hline GAT / Feiras & 0 & 0 & 0 & 0 & 0 & 0 & 1 & 0 & 0 & 0 & $\begin{array}{l}1 \\
1,10 \%\end{array}$ \\
\hline GAT / Gastronomia típica & 0 & 2 & 0 & 1 & 2 & 1 & 0 & 4 & 2 & 5 & $\begin{array}{l}17 \\
19,3 \%\end{array}$ \\
\hline GAT / Hotelaria & 0 & 0 & 0 & 0 & 0 & 1 & 0 & 0 & 0 & 0 & $\begin{array}{l}1 \\
1,10 \%\end{array}$ \\
\hline GAT / Mercado público & 0 & 0 & 0 & 0 & 0 & 0 & 0 & 1 & 1 & 0 & $\begin{array}{l}2 \\
2,24 \%\end{array}$ \\
\hline $\begin{array}{l}\text { GAT / Rest. e similares } \\
\text { como atrativos }\end{array}$ & 0 & 0 & 0 & 0 & 0 & 1 & 1 & 0 & 3 & 0 & $\begin{array}{l}5 \\
5,62 \%\end{array}$ \\
\hline $\begin{array}{l}\text { GAT / Rotas e Roteiros } \\
\text { Gastronômico }\end{array}$ & 0 & 1 & 0 & 0 & 0 & 0 & 0 & 1 & 1 & 0 & $\begin{array}{l}3 \\
3,37 \%\end{array}$ \\
\hline $\begin{array}{l}\text { Pesquisa sobre Tur. Gas- } \\
\text { tronômico }\end{array}$ & 0 & 0 & 0 & 1 & 0 & 0 & 0 & 0 & 0 & 0 & $\begin{array}{l}1 \\
1,10 \%\end{array}$ \\
\hline $\begin{array}{l}\text { Planejamento e Gestão } \\
\text { de Destinos Turísticos }\end{array}$ & 0 & 0 & 0 & 1 & 1 & 0 & 1 & 2 & 1 & 2 & $\begin{array}{l}8 \\
8,99 \%\end{array}$ \\
\hline Souvenir gastronômico & 0 & 0 & 0 & 0 & 0 & 0 & 0 & 0 & 0 & 1 & $\begin{array}{l}1 \\
1,10 \%\end{array}$ \\
\hline Sustentabilidade & 0 & 0 & 0 & 0 & 2 & 1 & 0 & 0 & 0 & 1 & $\begin{array}{l}4 \\
4,49 \%\end{array}$ \\
\hline TB / Enoturismo & 1 & 1 & 2 & 2 & 3 & 1 & 7 & 2 & 4 & 2 & $\begin{array}{l}25 \\
28,09 \%\end{array}$ \\
\hline TB / Turismo Cervejeiro & 0 & 0 & 0 & 0 & 0 & 0 & 0 & 0 & 1 & 1 & $\begin{array}{l}2 \\
2,24 \%\end{array}$ \\
\hline TB / Turismo de Cachaça & 0 & 0 & 0 & 0 & 0 & 0 & 0 & 2 & 0 & 0 & $\begin{array}{l}2 \\
2,24 \%\end{array}$ \\
\hline TB / Turismo de Café & 0 & 0 & 0 & 0 & 1 & 0 & 0 & 0 & 0 & 0 & 1 \\
\hline Total & 1 & 4 & 2 & 7 & 13 & 7 & 12 & 14 & 14 & 15 & 89 \\
\hline$\%$ & 1,1 & 4,49 & 2,4 & 7,86 & 14,5 & 7,85 & $\begin{array}{l}13,4 \\
7\end{array}$ & 15,7 & 15,7 & $\begin{array}{l}16,8 \\
4\end{array}$ & \\
\hline
\end{tabular}

Fonte: a autora (2018)

Verifica-se que a grande maioria das publicações se debruça sobre um objeto isolado e procura descrevê-lo em suas especificidades, o que permite indicar uma predominância de artigos que correspondam à perspectiva "the anedoctal" indicada por Hjalager \& Richards (2002), seguida pela abordagem "the simultaneous", desenvolvida principalmente nos estudos sobre a subtemática GAT/Gastronomia típica.

A análise dos procedimentos metodológicos utilizados é fundamental para compreender o status quo de uma área de pesquisa, por permitir conhecer as abordagens usadas para desenvolver as problemáticas. Constatou-se que 20 resumos $(22,47 \%)$ não apresentam informações sobre os procedimentos metodológicos utilizados. Com a leitura dos textos integrais, constatou-se que 5 artigos não enunciavam seus procedimentos metodológicos em nenhum trecho, embora a leitura tenha permitido constatar que 1 foi construído a partir de pesquisa bibliográfica e documental e 4, a partir de pesquisa bibliográfica. Considerando o total de artigos, 14 (15,73\%) foram apresentados como pesquisa bibliográfica, 10 (11,23\%) como estudos de caso, 9 (10,11\%) como pesquisa quantitativa, 7 (7,86\%) como pesquisa histórica, 4 $(4,49 \%)$ como estudo etnográfico e 1 (1,10\%) como estudo ex-post-facto. Os demais artigos (44 artigos ou 
49,43\%) apenas indicam os procedimentos de coleta de dados. 0 gráfico 5 apresenta os instrumentos de coleta utilizados nos artigos analisados:

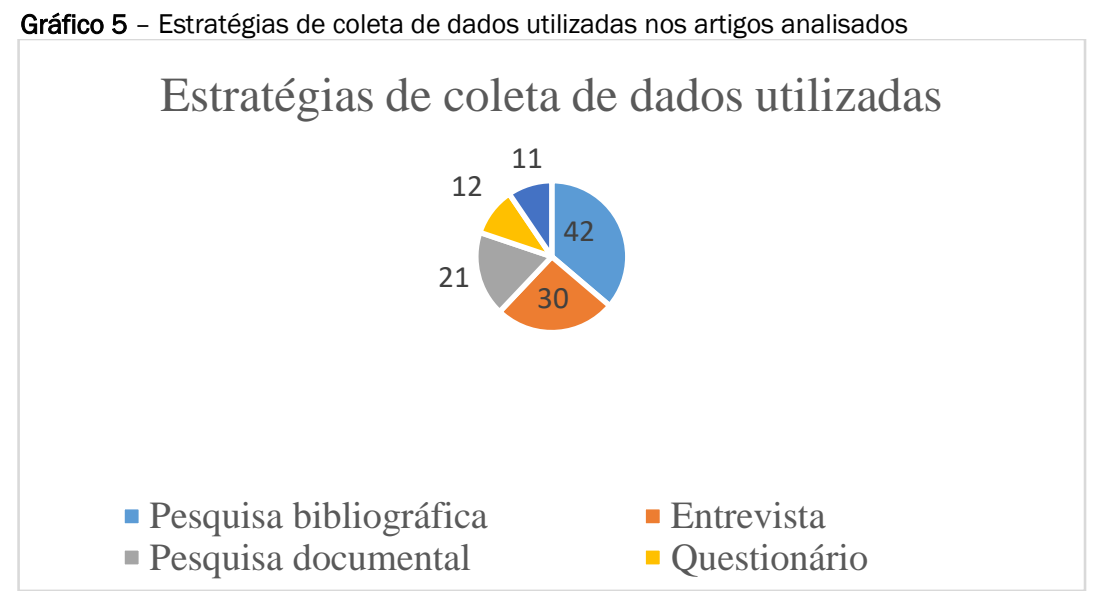

Fonte: a autora (2018)

Do total, 57 artigos (64,04\%) realizaram algum tipo de pesquisa de campo. Os dados obtidos por Okumus et al. (2018) indicam resultado semelhante, mesmo se tratando de um contexto internacional: $96 \%$ dos artigos analisados por esses autores são estudos empíricos, e apenas 4\% são artigos conceituais. Neste levantamento muitos artigos (43 ou 48,31\%) articulam mais de uma estratégia de coleta de dados, sendo a combinação mais usual pesquisa bibliográfica com entrevistas. A estratégia de coleta de dados mais utilizada é a pesquisa bibliográfica (42 ou 47,19\%), seguida pela realização de entrevistas (30 ou 33,7\%). Foram consideradas como "entrevistas" também as menções relacionadas à história oral, método de pesquisa historiográfica que se baseia na consulta a fontes orais a partir de uma entrevista. Na sequência, tem-se a pesquisa documental (21 ou 23,59\%), embora muitos artigos não mencionem as fontes documentais analisadas e os critérios de seleção destes documentos. Contudo, pode-se perceber que, dentre os documentos tratados, constam jornais impressos, cartazes de divulgação e cardápios.

As menções à técnica de observação incluem as indicações de "observação participante" (3 artigos), "visita in loco" (3 artigos), "observação direta” (1 artigo) e "observação” (4 artigos). E, apesar de apenas 9 artigos serem caracterizados como pesquisa quantitativa, 12 declaram a aplicação de questionários.

Okumus et al. (2018), ao analisarem os procedimentos de coleta de dados, identificaram 282 artigos que aplicaram questionário, 65 que usaram dados secundários, 39 que realizaram entrevistas, 23 que usaram simulação, 23 que aplicaram várias estratégias de coleta de dados e 18 estudos de caso. No levantamento realizado por Okumus et al. (2018) há predominância de pesquisas quantitativas. Barbosa \& Collaço (2018), embora não indiquem os números correspondentes, atestaram a predominância de métodos qualitativos, como observação participante, entrevistas e análise de conteúdo.

Neste levantamento constata-se expressiva predominância $(89,88 \%)$ pesquisa qualitativa, dados semelhantes aos encontrados por Ribeiro-Martins e Silveira-Martins (2018), que identificaram que 62,22\% dos artigos estudados são de caráter qualitativo, 31,11\% são de caráter quantitativo e apenas 6,66\% de caráter quali-quantitativo; e com os achados de Barbosa e Collaço (2018), que atestaram que apenas 1,28\% dos artigos estudados desenvolveram pesquisa quantitativa.

Verifica-se que, embora a pesquisa bibliográfica e documental sejam as estratégias mais indicadas, apenas 3 artigos (3,37\%) deste levantamento discutem aspectos teórico-conceituais (2 artigos para características gerais do Turismo Gastronômico e apenas 1 sobre a aplicações metodológicas associadas ao Turismo Gastronômico). Estes dados contrastam com os obtidos por Okumus et al. (2018), que identificaram que $64,7 \%$ dos artigos estudados tinha caráter quantitativo, 25,1\% tinham caráter qualitativo e 10,2\% eram de caráter quali-quantitativo. "Although many peers were attracted to quantitative research methods, a notably increasing trend in using qualitative and hybrid methods has accelerated the development of the food and gastronomy in the Hospitality and Tourism field" (Okumus et al., 2018, p. 69). Neste levantamento foram 
identificadas apenas $3(3,37 \%)$ artigos unindo estratégias qualitativas e quantitativas de pesquisa de campo, abordagem que tende a produzir dados mais robustos e uma compreensão mais ampla dos fenômenos estudados.

Uma crítica ao quadro geral encontrado é a de que muitos artigos apresentam um descritivo metodológico superficial, com destaque para pesquisas que desenvolvem pesquisa de campo sem esclarecer os critérios de dimensionamento, seleção e abordagem da amostra de respondentes. As carências identificadas nos descritivos metodológicos não apenas atrapalham a apreciação dos dados e da argumentação desenvolvida, mas também dificultam o desenvolvimento do quadro geral de produção do conhecimento sobre a área, tendo em vista que se torna impossível replicar estudos e aprimorar os métodos já utilizados.

Procurou-se perceber também se o Turismo Gastronômico é um tema recorrente de pesquisas ou se os autores se dedicaram a ele apenas eventualmente. Foram identificados 159 autores envolvidos nas publicações estudadas, e contabilizado o número de artigos publicado por cada autor, tem-se a tabela 3:

\begin{tabular}{ll} 
Tabela 3 - Quantidade de artigos publicado por cada autor & \\
\hline Quantidade de artigos publicados & Número de autores \\
\hline Um artigo & $138(86,79 \%)$ \\
Dois artigos & $10(6,29 \%)$ \\
Três artigos & $6(3,77 \%)$ \\
Quatro artigos & $3(1,89 \%)$ \\
Cinco artigos & $1(0,63 \%)$ \\
Seis artigos & $1(0,63 \%)$ \\
Total de autores envolvidos & $159(100 \%)$ \\
\hline
\end{tabular}

Fonte: a autora (2018)

A maioria dos autores possui uma única publicação (86,79\%), sendo que apenas 21 (13,2\%) publicaram mais de um artigo. Ribeiro-Martins e Silveira-Martins (2018, p.196) encontraram um resultado semelhante, com $95,79 \%$ dos autores publicando apenas um artigo, e observam que isto tende a inibir oportunidades de densificação, ampliação e exploração da teoria. Concorda-se com esta perspectiva, pois acredita-se ser fundamental a existência de pesquisadores que se dediquem de forma sistemática para que avanços teórico-metodológicos possam ocorrer. Okumus et al. (2018) identificaram 798 autores em seu levantamento e, destes, 638 publicaram apenas 1 artigo, 83 publicaram 2 artigos, 44 publicaram 3 artigos, 31 publicaram quatro ou mais artigos (sendo que o autor mais prolífico publicou 20 artigos). Verifica-se, portanto, uma tendência a publicações isoladas.

Um levantamento da formação dos pesquisadores com mais de uma publicação procurou identificar se Turismo e Gastronomia havia sido objeto de seus trabalhos de pós-graduação (dissertação e/ou tese) e se o pesquisador atualmente é orientador de um PPG. Dos 21 autores, 11 (52,38\%) são graduados em Turismo, 2 (9,52\%) em Turismo e Hotelaria e 7 (33,33\%\%) possuem formações diversas: Administração, Comunicação Social, Direito e Administração, Engenharia Mecânica e Administração, Geografia, Hotelaria, e Pedagogia. Não foi possível localizar o Currículo Lattes de um pesquisador.

Sobre a pós-graduação, 1 pesquisador possui apenas doutorado. Dos 20 pesquisadores que possuem mestrado, 7 (35\%) são mestres em Turismo; 2 (10\%) em Turismo e Hotelaria; 2 (10\%) em Geografia; 2 (10\%) em Administração e 7 (35\%) possuem formações diversas: em Administração, Antropologia, Artes Visuais, Ciências Políticas, Ciências Sociais Aplicadas, Educação e Sociologia. Dezesseis pesquisadores (76,19\%) são doutores, e um deles está cursando seu doutorado. Do total, 3 (18,75\%) possuem doutorado em Geografia, 3 (18,75\%) em Turismo, 2 (12,5\%) em História, 2 (12,5\%) em Administração, e 6 (37,5\%) possuem doutorados em diferentes áreas (Ciências da Comunicação, Comunicação Social; Desenvolvimento Rural, Geografia, Turismo e Hotelaria, Sociologia). Observa-se que estas combinações de formações tendem a propiciar abordagens multidisciplinares, mais favoráveis à compreensão do uso turístico de manifestações gastronômicas e correspondem às recomendações de Hjalager \& Richards (2002) e Scarpato (2002).

Sete pesquisadores $(33,33 \%)$ desenvolveram seu mestrado e seu doutorado sobre Turismo e Gastronomia, e $5(23,80 \%)$ dedicaram ou seu mestrado ou seu doutorado a este tema. Esses dados são tímidos, mas ainda assim favoráveis, tendo em vista que dissertações e teses são pesquisas de maior fôlego, que tendem a exigir uma discussão teórica e um conjunto de procedimentos metodológicos mais robusto, ressaltando- 
se ainda que teses de doutorado tem o compromisso de desenvolver abordagens inovadoras com contribuições teórico-metodológicas para as áreas de conhecimento. Seis pesquisadores atuam em PPG em Turismo e Hospitalidade: Universidade Anhembi Morumbi (2 autores), Universidade Federal do Paraná (2 autores), Universidade de Caxias do Sul (1 autor), Universidade do Vale do Itajaí (1 autor). Mesmo se tratando de um número reduzido, essa informação é revestida de importância: um orientador que possua experiência teórico-metodológica com o tema pode garantir não apenas uma maior abertura para pesquisas na área, mas também uma orientação especializada que aprimore abordagens teóricas e empíricas.

\section{CONCLUSÕES}

As relações entre a Gastronomia e o Turismo são múltiplas e complexas. A operacionalização de práticas alimentares, produtos e serviços gastronômicos como atrativos turísticos podem gerar implicações ambientais, sociais, culturais e financeiras de grande impacto local. Por consequência, trata-se de uma área de estudo profícua, mas de potencial pouco explorado, principalmente no Brasil.

Este artigo procurou compreender como a pesquisa sobre Turismo Gastronômico vem se desenvolvendo no país pelo estudo da produção científica em periódicos nacionais que ocupam diferentes estratos Qualis, e constatou que o interesse acadêmico sobre o tema ganhou materialidade no Brasil na primeira década de 2000, com as publicações dos livros de Schütler (2003) e Fagliari (2005) e do primeiro artigo sobre enoturismo na Turismo em Análise. Desde então, vários periódicos acolheram pesquisas da área, com o primeiro ápice de publicações em 2012 e a publicação de quatro Dossiês Temáticos por três periódicos, evidenciando o interesse de editores e pesquisadores em relação à temática.

As temáticas e subtemáticas identificadas demonstram as diferentes interfaces e consequentes abordagens acadêmicas que podem ser desenvolvidas, com destaque para o Turismo de Bebidas/Enoturismo, subsegmento que vem ganhando importância na oferta turística de diferentes localidades brasileiras. Como temáticas surgidas recentemente identificaram-se souvenir gastronômico e turismo cervejeiro.

A análise dos procedimentos metodológicos demonstrou a predominância expressiva de estudos qualitativos centrados em um único objeto de pesquisa e revelou uma constatação preocupante: muitos artigos apresentam descritivos pouco específicos, que não permitem uma apreciação adequada de como a pesquisa foi realizada.

Foi positivo constatar que 159 autores estão envolvidos nas publicações estudadas, embora a grande maioria tenha publicado um único artigo, repetindo uma tendência apontada por outros autores. Foi possível perceber um grupo, mesmo que pequeno, que vem se dedicando à área de forma sistemática, bem como identificou-se seis pesquisadores que atuam como orientadores em PPG, o que pode permitir uma orientação especializada para novos pesquisadores.

Constatou-se que a produção científica sobre Turismo Gastronômico no Brasil é recente, mas já apresenta um corpus de publicação que permite delinear um escopo de temáticas e subtemáticas razoavelmente amplo. A maior carência percebida diz respeito aos avanços teórico-metodológicos: além das lacunas nos descritivos metodológicos destaca-se a falta de textos dedicados ao desenvolvimento teórico sobre o tema. Em termos de desdobramentos deste artigo, identifica-se a necessidade de um aprofundamento da análise da construção do objeto e dos delineamentos metodológicos nos estudos sobre Turismo Gastronômico.

\section{REFERÊNCIAS}

Barbosa, F. \& Collaço, J. (2018). J. Eating identities and places. Antropology of food, 13. Disponivel em: Bardin, L. (2011). Análise de conteúdo. São Paulo: Edições 70. https://doi.org/10.4000/aof.8468

Barthes, R. (1997). Toward a psychosociology of contemporary food consumption. In: Counihan, C.; Esterik, P. Food and culture - a reader. Psychology Press: New York.

Bastos, S. \& Rejowski, M. (2015). Pesquisa científica em hospitalidade: desafios em busca de uma configuração teórica. Revista Hospitalidade, São Paulo, 12(Especial),132-159. Disponível em: https://www.revhosp.org/hospitalidade/article/view/575. Recuperado em 10/11/2018. 
Boutaud, J. (2001). Comensalidade. Partilhar a mesa. In: Montandon, A. (Org.). O livro da Hospitalidade. São Paulo: Senac.

Brasil. Ministério Da Educação (2016) Catálogo Nacional dos Cursos Superiores de Tecnologia. Disponível em: $\quad$ http://portaldoprofessor.mec.gov.br/storage/materiais/0000009402.PDF. Recuperado em 10/09/2018.

Brasil. Ministério do Turismo. Secretaria Nacional de Políticas de Turismo. Departamento de Estruturação, Articulação e Ordenamento Turístico. (2010) Turismo cultural: orientações básicas. $3^{a}$ ed. Brasília: MTur. Disponível em: http://www.turismo.gov.br/sites/default/turismo/o_ministerio/publicacoes/downloads_publicacoes/Turismo Cultural Versxo Final IMPRESSxO .pdf. Recuperado em 05.nov.2018.

CAPES - Coordenação de Aperfeiçoamento de Pessoal de Ensino Superior. (2018). Avaliação para PósGraduação - Qualis Periódico. Disponível em: https://www.capes.gov.br/perguntas-frequentes. Recuperado em 10/11/2018.

CNPq - Conselho Nacional de Desenvolvimento Científico e Tecnológico. (2018). Plataforma Lattes. Disponível em: http://lattes.cnpq.br/. Recuperado em 10/11/2018.

Collaço, J. (2013). Gastronomia: a trajetória de uma construção recente. Revista Habitus, Goiânia, 11(2), 203-222.

Costa, E. (2012). Turismo gourmand: o luxo e a gastronomia como vetores para o apetite de viajar. Turismo e Sociedade, 5(1). https://doi.org/10.5380/tes.v5i1.26584

Croce, E. \& Perri, G. (2010). Food and wine tourism. Cambridge: CABI.

Fagliari, G. (2005). Turismo e alimentação. Roca: São Paulo.

Gândara, J.; Gimenes, M. H. \& Mascarenhas, R. (2009). Reflexões sobre o Turismo Gastronômico na perspectiva da sociedade dos sonhos. In: Panosso Netto, A. \& Ansarah, M. (Org.). Segmentação do mercado turístico - estudos, produtos e perspectivas. Barueri: Manole.

Getz, D.; Robinson, R.; Anderson, T. \& Vujicic, S. (2014). Foodies \& Food Tourism. Goodfellow Publishers: Oxford.

Gimenes, M. H. (2012). Estudos sobre gastronomia no Brasil: um estudo exploratório descritivo sobre dissertações de mestrado concluídas entre 2007 e 2011. Revista Rosa dos Ventos, 4(3), 279-299, jul-set. Disponível em: http://www.ucs.br/etc/revistas/index.php/rosadosventos/article/view/1696/1114. Recuperado em: 08.nov.2018.

Gimenes-Minasse, M. H. \& Peccini, R. (2012). Editorial. Gastronomia e Turismo: abordagens acadêmicas. Revista Rosa dos Ventos, 4(3), jul/set. Disponível em: http://www.ucs.br/etc/revistas/index.php/rosadosventos/article/view/1762/pdf 79. Recuperado em: 08.nov.2018.

Gimenes-Minasse, M. H. (2015). A formação superior em gastronomia: análise descritiva das dissertações de mestrado produzidas no Brasil. Revista Brasileira de Pesquisa em Turismo, 9(1), jan./abr. https://doi.org/10.7784/rbtur.v9i1.703

Hall, C. M. \& Sharples, L. (2003). The consumption of experiences or the experience of consumption? An introduction to the tourism of taste. In: HALL, C. et al. (org.). Food Tourism around the world. Elsevier: Burlington, p. 1-24. https://doi.org/10.1016/B978-0-7506-5503-3.50004-X

Herrera, C.; Herranz, J. \& Arilla, J. (2012). Gastronomy`s importance in the development of tourism destinations in the world. UNTWO Global Report on Food Tourism, 6-9. Disponivel em: http://cf.cdn.unwto.org/sites/all/files/docpdf/amreports4-foodtourism.pdf. Recuperado em: 7.nov.2018.

Hjalager, A-M. \& Richards, G. (2002) Still undigested: research issues in tourism and gastronomy. Hjalager, A.-M. \& Richards, G. (org). Tourism and gastronomy. New York: Routledge, 2002. https://doi.org/10.4324/9780203218617

Kesimoglu, A. (2015). A reconceptualization of gastronomy as relational and reflexive. Hospitality \& Society, 5(1), 71-92. https://doi.org/10.1386/hosp.5.1.71_1

Mitchell, R. \& Hall, C. (2003). Consuming tourists: Food Tourism, consumer behavior.In: Hall, C. M. et al. (org.). Food Tourism around the world. Elsevier: Burlington, p.60-80. https://doi.org/10.1016/B978-0-75065503-3.50006-3

Montandon, A. (2011). Espelhos da hospitalidade. In: Montandon, A. (org). O livro da hospitalidade. São Paulo: Senac. 
Ribeiro-Martins, C. \& Silveira-Martins, E. (2018). Turismo gastronômico: uma pesquisa bibliométrica em bases de dados nacionais e internacionais. Revista Turismo - Visão e Ação, 20(1), jan-abr. https://doi.org/10.14210/rtva.v20n1.p184-208

Richards, G. (2002). Gastronomy: an essential ingredient in tourism production and consumption? In: Hjalger, A-M. \& Richards, G. (org). Tourism and gastronomy. Routledge, p.3-20.

Santich, B. (2004). The study of gastronomy and its relevance to hospitality education and training. International Journal of Hospitality Management, 23, 15-24. https://doi.org/10.1016/S0278-4319(03)00069-0

Santos, G. \& Rejowski, M. (2013). Comunicação científica em Turismo no Brasil: análises descritivas de periódicos nacionais entre 1990 e 2012. Revista Brasileira de Pesquisa em Turismo, 7(1). https://doi.org/10.7784/rbtur.v7i1.578

Scarpato, R. (2002). Gastronomy studies in search of hospitality. Journal of Hospitality and Tourism Management, 9(2), jun., 1-12. Disponível em: http://foodandtravelcommunications.info/about/GastrnomyStudiesHospitality.pdf. Recuperado 11.nov.2018.

Schlüter, R. (2006). Turismo y património gastronómico. Buenos Aires: CIET.

UNWTO. (2015). Global Report on Gastronomy. UNWTO: Madrid. Disponível em: https://www.eunwto.org/doi/pdf/10.18111/9789284414819.1. Recuperado em: 23.set.2018.

UNWTO. (2017). Second Global Report on Gastronomy. UNWTO: Madrid. Disponível em: http://cf.cdn.unwto.org/sites/all/files/pdf/gastronomy_report_web.pdf. Recuperado em: 23.set.2018.

\section{Informações sobre a autora}

\section{Maria Henriqueta Sperandio Garcia Gimenes Minasse}

Bacharel em Turismo, Mestre em Sociologia, Doutora em História. Professora no Mestrado em Hospitalidade e no Mestrado Profissional em Administração - Gestão em Alimentos e Bebidas da Universidade Anhembi Morumbi.

E-mail: mariegimenes@gmail.com

ORCID: http://orcid.org/0000-0002-4952-808X 